\title{
Luksering av hofteprotese
}

\begin{abstract}
BAKGRUNN Frekvensen av hofteproteseluksering blir i litteraturen oppgjeve til 2-3\%. Luksasjon kan ha mange årsaker, som forhold ved pasient, operatør, protesetype eller operasjon. Målet med denne studien var å finne frekvens, årsaker til og behandling av luksasjon ved vår avdeling.
\end{abstract}

MATERIALE OG METODE Materialet består av alle pasientar som blei opererte med hofteprotese ved Ortopedisk seksjon, Haugesund sjukehus, frå 1987 til og med 2011. Informasjonen er innhenta retrospektivt frå databasar og pasientjournalar etter gjennomsnittleg 6,1 år.

RESULTAT 2236 pasientar fekk hofteprotese i perioden. $72 \%$ var kvinner. 548 fekk ITH-protese med stor caput (32 eller $28 \mathrm{~mm}$ diameter), 1290 fekk Charnley-protese med $22 \mathrm{~mm}$ diameter. Lubinus Spll blei brukt hos 299 og Landos Corail hos 99 , alle med $28 \mathrm{~mm}$ caputdiameter. Hos 75 pasientar $(3,4 \%)$ hadde protesen luksert. Det var ingen signifikant forskjell i lukseringsfrekvens mellom dei fire protesetypane. Protesar med caputdiameter $32 \mathrm{~mm}$ hadde signifikant mindre luksering enn dei andre $(2,0 \%$ og $3,6 \%, p=0,03)$.

TOLKING Våre resultat samsvarer stort sett med det andre har funne. I dette retrospektive materialet fekk om lag tredelen av pasientane med hofteprotesar som lukserte, fleire lukseringar.

Luksasjonstendens eller ustabilitet er eit viktig kvalitetsmål for hofteprotesekirurgi. Luksasjon er, nest etter losning, den vanlegaste større komplikasjonen til slik kirurgi og sannsynlegvis eit aukande problem (1). I motsetning til losning oppstår luksasjon kort tid etter inngrepet, ofte innan ein månad. I litteraturen er luksasjonsfrekvensen $2-3 \%(2-13)$.

Årsakene er multifaktorielle $(7,8)$. Det kan vere forhold ved pasient, operatør, protesetype eller inngrepet. Årsaka kan også vere reint mekanisk, med feilstilling av protesedelar. Det kan vere retroversjon eller for stor anteversjon eller kombinasjonar av feilstilling av både femur- og acetabularkomponenten. For slakk kapsel eller slapp muskulatur kan bidra til instabilitet. Abduktormuskulaturen kan svikte på grunn av nerve- eller karskade, særleg etter revisjonsoperasjon. Traume, slik som eit fall, kan også vere årsak til luksering. Enkelte har funne høgare luksasjonsfrekvens ved sekvele etter collumfraktur enn etter artrose (5) og høgare frekvens etter revisjon. I det siste er det blitt sett søkelys på samanhengen mellom protesediameter og lukseringsfare (13-16).

Som eit ledd i kvalitetskontrollen av vår hofteprotesekirurgi var målet med denne gjennomgangen å finne frekvensen av proteseluksasjon ved avdelinga vår og førekomsten av ulike risikofaktorar, inkludert protesar med liten caputdiameter.

\section{Materiale og metode}

Materialet består av alle pasientane som blei opererte med hofteprotese ved Ortopedisk seksjon ved Haugesund sjukehus frå 1987 til og med 2011. Informasjonen er innhenta retrospektivt gjennomsnittleg 6,1 år etter primæroperasjonen. Vi har fått datautskrifter frå leddproteseregisteret, gjennomgått vår lokale database med demografiske data og komplettert med pasientjournalar ved behov. Delar av datasettet er tidlegare publisert i Tidsskriftet (17).

Ved avdelinga gjerast det hofteproteskirurgi av eller under oppsyn av spesialist $i$ ortopedisk kirurgi. Rutinen er at femurdelen blir sett i nøytral stilling eller med lett anteversjon. Vi prøver å sette acetabularkomponenten i om lag $45^{\circ}$ i frontalplanet og med ingen eller lett anteversjon.

Til analyse er brukt programpakka Statistica for Windows, Release 10, 2010 (Stat Soft Inc., Tulsa, OK). P-verdiar $<0,05$ blei rekna som statistisk signifikante, uansett metode. Prosjektet er vurdert og godkjend av Personvernombudet.

\section{Resultat}

2236 pasientar fekk hofteprotese i perioden. $28 \%$ var menn. Alderen ved operasjonstidspunktet var i gjennomsnitt 69,9 år, 68,0 år for menn og 70,6 år for kvinner. Ved 2158 av operasjonane $(96,5 \%)$ vart det brukt lateral tilgang. For resten vart det brukt framre tilgang med miniinvasiv teknikk. 271 pasientar $(12 \%)$ vart opererte med trochan-

1290 pasientar vart opererte med Charnley-protese med caputdiameter på $22 \mathrm{~mm}$ og 548 med ITH-protese med caputdiameter på $32 \mathrm{~mm}$ (350 pasientar) eller $28 \mathrm{~mm}$ (198 pasientar). 41 av dei som fekk ITH-protese hadde sementfri acetabularkopp. Lubinus terosteotomi.

\author{
Birger Valen \\ birger.valen@get.mail.no \\ Ortopedisk seksjon \\ Haugesund sjukehus
}

DE

Engelsk omsetjing på www.tidsskriftet.no

\section{HOVUDBODSKAP}

Vel $3 \%$ av hofteprotesane lukserte

Protesar med stor caputdiameter hadde mindre lukseringstendens

Om lag tredelen av dei med luksering fekk fleire lukseringar 
SP2 vart brukt hos 299 pasientar og Landos Corail hos 99, begge typar med caputdiameter $28 \mathrm{~mm}$.

Ved gjennomgang gjennomsnittleg 6,1 år etter primæroperasjonen (variasjon 0,2-23 år) fann vi at protesen hadde luksert hos 75 pasientar $(3,4 \%)$. Gjennomsnittsalder ved operasjonen for desse 75 var berre insignifikant høgare enn for resten, og det var heller ingen signifikant kjønnsforskjell. Første gongs luksering skjedde gjennomsnittleg 3,4 år postoperativt (spreiing 1 dag-22 år). Median tid til første luksering var 55 dagar.

Journalgjenomgangen gav informasjon om skademekanismen hos 68 av 75 pasientar. Hos 59 pasientar (87\%) skjedde lukseringa første gong under dagleg aktivitet, som å reise seg fra ein stol, hos ni etter eit fall $(13 \%)$. Til saman hadde dei 75 pasientane 177 registrerte lukseringar. Alle dei 177 reponeringane unntatt ein er gjort lukka. Vi har totaltal for lukseringar for 72 pasientar 29 hadde berre eitt tilfelle av luksasjon, 19 hadde to og 24 hadde 3-8 luksasjonar (residiverande luksering).

Desse 24 pasientane var kandidatar for meir omfattande tiltak, og 20 av dei vart reopererte. 11 vart reopererte med PLADteknikk (PLAD = posterior labrum augmenting device), som gjev ekstra mekanisk hinder baktil i acetabulum. Tre av dei har hatt ein ny lukseringsepisode etter prosedyren. $\mathrm{Ni}$ andre gjennomgjekk revisjon og oppnådde stabilitet. Av dei blei det gjort forlenging av femurkomponenten hos fire og utskifting av for steil acetabulum hos fire andre. Hos ein er det gjort fjerning av beinpåleiring ved acetabulumkanten. Hos dei 350 pasientane som fekk protese med caputdiameter $32 \mathrm{~mm}$, var lukseringsfrekvensen $2,0 \%$. Det var ingen signifikant forskjell lukseringsfrekvens mellom dei fire protesetypane. Det var derimot signifikant mindre luksering for 350 pasientar med $32 \mathrm{~mm}$ diameter på protesehovudet samanlikna med dei resterande 1886 pasientane, $(2,0 \%$ og $3,6 \%, p=0,03)$.

For residiverande luksering var det ikkje signifikant forskjell i førekomst mellom dei fire protesemodellane, og det var ingen signifikant forskjell i lukseringsfrekvens mellom framre miniinvasiv tilgang og lateral tilgang.

\section{Diskusjon}

Vår luksasjonsfrekvens på 3,4 \% for hofteprotesar samsvarer om lag med det andre har funne (2-12). Årsakene til luksering er multifaktorielle, og ofte finn ein ingen forklaring. Vi fann som andre ingen samanheng mellom luksering og høg alder (15). Andre har funne det motsette (12). Gjennomsnittsalder ved operasjonen var nesten 70 år, og begynnande demens kan av og til vere årsak i denne aldersgruppa (4). I andre studiar er det, som i vår, ikkje påvist signifikant kjønnsforskjell $(7,8,15)$, men i to studiar fann dei størst lukseringsfrekvens for kvinner $(6,12)$

I fleire studiar har dei funne auka luksering ved bakre tilgang og gode resultat ved den laterale, som var vår standardmetode $(6$, $8,12,16,18-20)$. Vi fann ingen signifikan forskjell mellom lateral og framre tilgang.

I tre studiar $(13,15,16)$ var det, som hos oss, lågare lukseringsfrekvens for store proteseshovud - $32 \mathrm{~mm}$ diameter. I ein studie blei det konkludert at ein av den grunn bør bruke $32 \mathrm{~mm}$ hovud (15). Tidlegare var ein tilbakehalden med dette alternativet på grunn av auka plastslitasje, men betre plastkvalite har gjort at dette problemet no er løyst (15). I to andre studiar var det ingen slik samanheng $(2,6)$. Protesemodellane har ulik konstruksjon med ulik lengde på halsen og ulik caputdiameter. Dette verkar sannsynlegvis inn på luksasjonstendensen $(8,13,14,19)$.

Tekniske problem med operasjonen, som feilstilling av protesekomponentar, for steil eller feilrotert acetabularkomponent, blir ofte oppgjeve som luksasjonsårsak $(3,21)$. I ein studie var det ingen korrelasjon mellom for steil acetabulum og luksering (7). Ein sjeldan gong kan også feilrotert femurdel vere årsak (3).

Manglande erfaring hos operatøren kan vere medverkande årsak til luksering $(2,10$ 19). Alle dei aktuelle 75 operasjonane i studien vår var utførte av eller under oppsyn av erfarne operatørar.

I fleire studiar skiljer ein mellom tidlege og seine (etter fem år) lukseringar $(19,22$, 23). At det er størst fare for luksering kort tid etter operasjonen, er i samsvar med mange andre studiar $(3,7,15,24)$. Ved seine lukseringar kan også slitasje av acetabulardelen verke inn $(19,22,23)$, og dette kan ofte vere indikasjon for operativ revisjon $(22,23)$. Det akutte problemet lar seg nesten alltid løyse med lukka reponering $(3,6,15,25)$. Av og til trengst open reponering på grunn av inneklemming av kapsel eller sene (3). At om lag ein tredel berre får ei enkelt luksering, samsvarer med andre rapportar (24).

Ved mange lukseringar er det uråd å finne sikker forklåring (26). Vel ein tredel fekk residiverande luksasjonar $(3,4,9)$, og desse pasientane var kandidatar for ny operasjon for å oppnå stabilisering $(3,6,18,27)$. Ein annan studie viste at om lag $50 \%$ ville trenge reoperasjon (28). Før reoperasjon og korrigering må ein prøve å finne eksakt årsak til problemet $(18,24,29)$. Dette kan vere vanskeleg, og vanleg røntgenundersøking gjev ofte lite forklåring på lukseringa (7). For å avklare feilstilling må ein gjere CT-undersøking, som syner stilling på både femur- og acetabulardelen (26). Den mest effektive prosedyren er reorientering av ein retrovertert acetabularkomponent (18). Forlenging av femurdelen til lengre hals kan også bli aktuelt (25).

Vi fann, som andre, tilfredsstillande resultat ved PLAD-bruk $(30,31)$
Birger Valen (f. 1946)

er spesialist i ortopedisk kirurgi.

Forfattaren har fylt ut ICMJE-skjemaet og oppgjev ingen interessekonfliktar.

\section{Litteratur}

1. Fevang BT, Lie SA, Havelin LI et al. Improved results of primary total hip replacement. Acta Orthop 2010: 81: 649-59.

2. Hedlundh $U$, Ahnfelt $L$, Hybbinette $\mathrm{CH}$ et al. Surgical experience related to dislocations after total hip arthroplasty. J Bone Joint Surg Br 1996; 78 : $206-9$

3. Ali Kahn MA, Brakenbury PH, Reynolds IS. Dislocations following total hip replacement. J Bone Joint Surg Br 1981; 63-B: 214-8

4. Lindberg HO, Carlsson AS, Gentz CF et al. Recurrent and non-recurrent dislocation following total hip arthroplasty. Acta Orthop Scand 1982; 53: 947-52

5. Hedlundh U, Fredin H. Patient characteristics in dislocations after primary total hip arthroplasty. 60 patients compared with a control group. Acta Orthop Scand 1995; 66: 225-8.

6. Woo RY, Morrey BF. Dislocations after total hip arthroplasty. J Bone Joint Surg Am 1982; 64: 1295-306.

7. Paterno SA, Lachiewicz PF, Kelley SS. The influence of patient-related factors and the position of the acetabular component on the rate of dislocation after total hip replacement. J Bone Joint Surg Am 1997: 79: 1202-10.

8. Turner RS. Postoperative total hip prosthetic femoral head dislocations. Incidence, etiologic factors, and management. Clin Orthop Relat Res 1994: 301: 196-204

9. Kristiansen B, Jørgensen L, Hölmich P. Dislocation following total hip arthroplasty. Arch Orthop Trauma Surg 1985; 103: 375-7

10. Hedlundh U, Hybbinette $\mathrm{CH}$, Fredin $\mathrm{H}$. Influence of surgical approach on dislocations after Charnley hip arthroplasty. J Arthroplasty 1995; 10: 609-14.

11. Mohr E, Indrekvam K. Kvalitetssikring av hoftepro tesekirurgi. Ny type hofteproteser, gjennomgang av et treårsmateriale. Tidsskr Nor Lægeforen 1996: 116 : 846-8

12. Morrey BF. Difficult complications after hip joint replacement. Dislocation. Clin Orthop Relat Res 1997: 344: 179-87.

13. Berry DJ, von Knoch M. Schleck CD et al. Effect of femoral head diameter and operative approach on risk of dislocation after primary total hip arthroplasty. J Bone Joint Surg Am 2005; 87 $2456-63$

14. Howie DW, Holubowycz OT, Middleton R. Large femoral heads decrease the incidence of dislocation after total hip arthroplasty: a randomized controlled trial. J Bone Joint Surg Am 2012; 94 1095-102.

15. Amlie $E, H ø v i k ~ \emptyset$, Reikerås 0 . Dislocation after total hip arthroplasty with 28 and 32-mm femoral head. J Orthop Traumatol 2010; 11: 111-5.

16. Byström S, Espehaug B, Furnes 0 et al. Femoral head size is a risk factor for total hip luxation a study of 42,987 primary hip arthroplasties from the Norwegian Arthroplasty Register. Acta Orthop Scand 2003; 74: 514-24.

17. Valen B. Luksasjon av hofteprotese. Tidsskr Nor aegeforen 2001: 121: 3054-6.

18. Morrey BF. Instability after total hip arthroplasty. Orthop Clin North Am 1992; 23: 237-48.

19. Hedlundh $\mathrm{U}$, Ahnfelt $\mathrm{L}$, Hybbinette $\mathrm{CH}$ et al. Dislocations and the femoral head size in primary tota hip arthroplasty. Clin Orthop Relat Res 1996: 333 226-33.

20. Demos HA, Rorabeck CH, Bourne RB et al. Instabi lity in primary total hip arthroplasty with the direc lateral approach. Clin Orthop Relat Res 2001; 393 . $168-80$

21. Biedermann R, Tonin A, Krismer M et al. Reducing the risk of dislocation after total hip arthroplasty: the effect of orientation of the acetabular component. J Bone Joint Surg Br 2005; 87: 762-9. 
22. Pulido L, Restrepo C, Parvizi J. Late instability following total hip arthroplasty. Clin Med Res 2007; 5: $139-42$.

23. von Knoch M, Berry DJ, Harmsen WS et al. Late dislocation after total hip arthroplasty. J Bone Joint Surg Am 2002; 84-A: 1949-53.

24. Suva D, Lübbeke A, Pagano F et al. Dislocation of a total hip prosthesis: etiology and treatment. Rev Med Suisse 2009; 5: 2544-8, 2550.

25. Dorr LD, Wolf AW, Chandler R et al. Classification and treatment of dislocations of total hip arthroplasty. Clin Orthop Relat Res 1983; 173: 151-8.

26. Pierchon F, Pasquier G, Cotten A et al. Causes of dislocation of total hip arthroplasty. CT study of component alignment. J Bone Joint Surg Br 1994; 76: $45-8$

27. Dorr LD, Wan Z. Causes of and treatment protocol for instability of total hip replacement. Clin Orthop Relat Res 1998; 355: 144-51.

28. Kotwal RS, Ganapathi M, John A et al. Outcome of treatment for dislocation after primary total hip repalcement. J Bone Joint Surg Br 2005; 87: $762-9$.

29. Daly PJ, Morrey BF. Operative correction of an unstable total hip arthroplasty. J Bone Joint Surg Am 1992; 74: 1334-43.

30. Charlwood AP, Thompson NW, Thompson NS et al. Recurrent hip arthroplasty dislocation: good outcome after cup augmentation in 20 patients followed for 2 years. Acta Orthop Scand 2002; 73 502-5.

31. McConway J, O'Brian S, Doran E et al. The use of posterior lip augmentation device for a revision of current dislocation. J Bone Joint Surg Br 2007; 89: $1581-5$.

Mottatt 6.2. 2012, første revisjon innsendt 12.7. 2012, godkjent 16.4. 2013. Medisinsk redaktør Are Brean. 